\title{
Effects of soil stoichiometry of the $\mathrm{CaCO}_{3}$ /available phosphorus ratio on plant density in Artemisia ordosica communities
}

\author{
ZHAO XueLai $^{1}$, HE XingDong ${ }^{1 *}$, XUE PingPing ${ }^{1}$, ZHANG Ning $^{1}$, WU Wei ${ }^{1}$, LI Rong ${ }^{1}$, \\ CI HuaCong ${ }^{1}$, XU JingJing ${ }^{1}$, GAO YuBao ${ }^{1} \&$ ZHAO HaLin ${ }^{2}$ \\ ${ }^{1}$ College of Life Sciences, Nankai University, Tianjin 300071, China; \\ ${ }^{2}$ Cold and Arid Regions Environmental and Engineering Research Institute, Chinese Academy of Sciences, Lanzhou 730000, China
}

Received August 9, 2011; accepted September 21, 2011; published online December 2, 2011

\begin{abstract}
In soil, $\mathrm{CaCO}_{3}$ can reduce the availability of phosphorus in arid and semi-arid regions, thereby influencing plant growth. However, the effects of soil stoichiometry of the $\mathrm{CaCO}_{3}$ /available phosphorus ratio $\left(\mathrm{CaCO}_{3} / \mathrm{AP}\right.$ ratio) on plant density are unknown. In this study, we examined 4 Artemisia ordosica communities located in arid and semi-arid regions, and performed a pot experiment with an orthogonal design to examine the relationships between the soil $\mathrm{CaCO}_{3} / \mathrm{AP}$ ratio and plant density. The results showed that the soil stoichiometry of the $\mathrm{CaCO}_{3} / \mathrm{AP}$ ratio had a greater effect on growth of $A$. ordosica than either $\mathrm{CaCO}_{3}$ or AP as single factor. The influence of the soil $\mathrm{CaCO}_{3} / \mathrm{AP}$ ratio on density of $A$. ordosica was related to the climatic zone and the types and/or amplitudes of increases in the soil $\mathrm{CaCO}_{3} / \mathrm{AP}$ ratio. When the soil $\mathrm{CaCO}_{3} / \mathrm{AP}$ ratio was within the same amplitude and was less than 2.5, the A. ordosica density increased in the semi-arid region, whereas the density decreased with increasing soil $\mathrm{CaCO}_{3} / \mathrm{AP}$ ratios in the arid region. In the semi-arid region, when the soil $\mathrm{CaCO}_{3} / \mathrm{AP}$ ratio was within the same amplitude and the increase in the soil $\mathrm{CaCO}_{3}$ content was greater than the increase in soil AP, the $A$. ordosica density increased with increasing soil $\mathrm{CaCO}_{3} / \mathrm{AP}$ ratios. This means that the relationship between the soil $\mathrm{CaCO}_{3} / \mathrm{AP}$ ratio and the $A$. ordosica density remained the same. In the arid region, an increase in the soil $\mathrm{CaCO}_{3} / \mathrm{AP}$ ratio as a result of increased soil $\mathrm{CaCO}_{3}$ content and decreased soil AP resulted in increased density of $A$. ordosica. Therefore, the relationship between soil $\mathrm{CaCO}_{3} / \mathrm{AP}$ ratios and density of $A$. ordosica was altered by these changes in soil chemistry. Thus, the soil stoichiometry of the $\mathrm{CaCO}_{3} / \mathrm{AP}$ ratio is an important factor affecting the density of A. ordosica in arid and semi-arid regions.
\end{abstract}

Artemisia ordosica, soil $\mathrm{CaCO}_{3}$, soil available phosphorus, soil $\mathrm{CaCO}_{3} /$ available phosphorus ratio (soil $\mathrm{CaCO}_{3} / \mathrm{AP}$ ratio), stoichiometry, plant density

Citation: Zhao X L, He X D, Xue P P, et al. Effects of soil stoichiometry of the $\mathrm{CaCO}_{3} /$ available phosphorus ratio on plant density in Artemisia ordosica communities. Chin Sci Bull, 2012, 57: 492-499, doi: 10.1007/s11434-011-4866-4

Ecological stoichiometry is a new research field for ecology [1-3]. During the process of asexual- and sexual-reproduction of organisms, variations in soil stoichiometry can lead to changes in biological stoichiometry, which can influence interspecies relationships within plant communities in various ecosystems with different energy inputs and nutrient supplies [4]. Soil stoichiometry and its dynamics, therefore, are important factors to take into account when evaluating limiting elements, nutrient use efficiency, population dynamics,

*Corresponding author (email: xingd@nankai.edu.cn) and community succession [5,6]. Studies on ecological stoichiometry provide a new way to study the interactions between soil and plants.

In arid and semi-arid regions, soil $\mathrm{CaCO}_{3}$ and available phosphorus (AP) are important factors for plant growth [7-9]. However, soil $\mathrm{CaCO}_{3}$ readily immobilizes AP as a result of adsorption and precipitation [10,11]. Higher levels of $\mathrm{CaCO}_{3}$ in the soil greatly decrease phosphorus availability, which strongly affects plants in arid and semi-arid regions because there is little precipitation $[10,12,13]$. The phosphorus limitation will then affect plant growth and even 
plant density within communities. As stated in Tilman's resource-ratio hypothesis, when the relative availability of limiting resources changes, plant species will specialize to secure different proportions of limiting resources, and then the composition of the plant community, i.e., plant density, will change [14]. However, at present, it is unknown whether plant density is affected by the soil stoichiometry of the $\mathrm{CaCO}_{3} / \mathrm{AP}$ ratio, which reflects the degree of immobilization of $\mathrm{AP}$ by $\mathrm{CaCO}_{3}$.

Theoretical analyses indicate that the soil stoichiometry of the $\mathrm{CaCO}_{3} / \mathrm{AP}$ ratio will influence plant growth in arid and semi-arid regions. It will initially influence plant biomass, and then affect plant density. For this study, we selected A. ordosica as the test species, and investigated four A. ordosica communities located in arid and semi-arid regions. We performed a pot experiment with an orthogonal design to examine the relationships between the soil $\mathrm{CaCO}_{3} /$ AP ratio and plant density. Our objectives were as follows: (1) to determine whether soil stoichiometry of the Ca$\mathrm{CO}_{3} / \mathrm{AP}$ ratio is a factor influencing plant density; and (2) to determine how plant density responds to different types/ amplitudes of changes in the soil stoichiometry of the $\mathrm{CaCO}_{3} /$ AP ratio.

\section{Materials and methods}

In this study, we carried out field surveys and a pot experiment from 2004 to 2011.

\subsection{Field studies}

We selected 4 sample plots for detailed surveys: a one-dimensional sample plot in an A. ordosica community on a fixed dune in Shapotou, Ningxia Hui Autonomous Region; a one-dimensional plot in an A. ordosica community on a semi-fixed dune and a two-dimensional plot in an A. ordosica community on a fixed dune in Yulin, Shaanxi Province; and a two-dimensional plot in an A. ordosica + A. frigida community on an overgrown sand dune in Alxa, Inner Mongolia Autonomous Region. Here, the definitions of fixed dune, semi-fixed dune, and overgrown sand dune are as described by Zhu [15] and Zhao [16].

The one-dimensional plot in Shapotou is in the artificial vegetation area built in 1974 at the Research Station of Chinese Academy of Sciences located on the south-eastern boundary of the Tengger Desert, located at $37^{\circ} 32^{\prime} 10^{\prime \prime} \mathrm{N}$, $105^{\circ} 02^{\prime} 07^{\prime \prime} \mathrm{E}$, in an arid area. The average annual air temperature is $9.6^{\circ} \mathrm{C}$. The average annual precipitation is $186.6 \mathrm{~mm}$ and average annual evaporation is $3000.7 \mathrm{~mm}$. The Aeolian landform type here is checkerboard sand dune. The community is dominated by A. ordosica, with a few individuals of Bassia dasphylla, A. scoparia, Eragrostis poaeoides, and others.

The one-dimensional and two-dimensional plots in Yulin are both in the Nansha air-seeding afforestation area in Qinhe, a town located on $\mathrm{Mu}$ Us Sand Land, located at $38^{\circ} 17^{\prime} 37^{\prime \prime} \mathrm{N}, 109^{\circ} 40^{\prime} 14^{\prime \prime} \mathrm{E}$, which lies in a semi-arid area. The average annual air temperature is $8.1^{\circ} \mathrm{C}$. The annual precipitation is $414 \mathrm{~mm}$ and annual evaporation is $1905 \mathrm{~mm}$. The Aeolian landform type in this area is faveolate semifixed and fixed sand dune. In the two sample plots, the plant communities are dominated by A. ordosica, with a few individuals of Agriophyllum squarrosum, Psammochloa villosa, Corispermum mongolicum, Salsola collina, and others.

The two-dimensional plot in Alxa is 5-km away from the Alxa Left Banner on the eastern boundary of Tengger Desert, which is located at $38^{\circ} 24^{\prime} 36^{\prime \prime} \mathrm{N}, 105^{\circ} 43^{\prime} 18^{\prime \prime} \mathrm{E}$, in an arid area. The average annual air temperature is $7.6^{\circ} \mathrm{C}$. The average annual precipitation is $213.1 \mathrm{~mm}$ and average annual evaporation is $2349.2 \mathrm{~mm}$. The community is in succession, and A. frigida is replacing A. ordosica. Co-occurring species in this community include E. poaeoides, Ferula bungeana, A. scoparia, Cleistogenes squarrosa, Stipa glareosa, Calligonum mongolicum and others.

In July, 2004, we established one-dimensional sample plots in A. ordosica communities on the semi-fixed dune of Yulin and the fixed dune of Shapotou. In each sample plot, we laid out a 500-m sample line in an east-west direction, and then placed $4 \mathrm{~m} \times 4 \mathrm{~m}$ quadrats at $10-\mathrm{m}$ intervals along the sample line, giving a total of 50 quadrats per sample line. In each quadrat, we recorded plant species and abundance, and collected mixed soil samples from the 0-20 cm layer. The soil samples were taken back to the laboratory for analysis.

In September, 2009, we established two-dimensional plots in the $A$. ordosica $+A$. frigida community on the overgrown sand dune of Alxa and in the A. ordosica community on the fixed sand dune of Yulin. Each sample plot covered an area of $40 \mathrm{~m} \times 40 \mathrm{~m}$, comprising 100 quadrats of $4 \mathrm{~m} \times 4 \mathrm{~m}$. We recorded species and abundance in each quadrat, and collected mixed soil samples from the 0-20 cm layer for analysis. The samples were collected from the $0-20 \mathrm{~cm}$ layer because the calcic horizon has formed at $20-40 \mathrm{~cm}$ depth in Alxa, as determined in our previous study [17].

\subsection{Pot experiment}

We performed a pot experiment with an orthogonal design in a greenhouse at the College of Life Sciences, Nankai University. The orthogonal array was $L_{16}\left(4^{5}\right)$ with 3 replicates for each treatment. The 4 levels of soil $\mathrm{CaCO}_{3}$ were 1 , 5,25 and $100 \mathrm{~g} \mathrm{~kg}^{-1}$ soil, and the 4 levels of soil AP were $0.1,3,6$ and $12 \mathrm{mg} \mathrm{kg}^{-1}$ soil. The 4 irrigation levels were 200, 250, 300, and $350 \mathrm{~g}$ water at each irrigation time. We aimed to examine the effects of the soil $\mathrm{CaCO}_{3} / \mathrm{AP}$ ratio within three factors.

The seeds of $A$. ordosica used for the pot experiment were collected from Alxa in the Tengger Desert. The sand matrix used in the pot experiments was also obtained from 
the Tengger Desert. The A. ordosica seeds were sown on 15 October 2010 into substrate (turf soil:perlite $=1: 1, \mathrm{v} / \mathrm{v}$ ) in PVC containers. Three or 4 seeds were sown in each container and were covered with a thin paper film. The paper film was removed after germination and the soil mix was kept moist.

The experimental treatments commenced on December 15, 2010. According to the treatment levels in the experimental design, we added appropriate amounts of $\mathrm{CaCO}_{3}$ and phosphorus to separate portions of sand, mixed each portion well, and then used them to fill numbered PVC pots $(195 \mathrm{~mm}$ high, $165 \mathrm{~cm}$ in diameter). The soil in each pot was $12 \mathrm{~cm}$ deep and $2 \mathrm{~kg}$ in weight. Seedlings were transplanted into the pots (one seedling/pot). During this process, we divided the $A$. ordosica seedlings into 3 size classes: larger, medium, and smaller, and each treatment included all 3 sizes as the 3 replicates. After transplantation, seedlings were watered with $400 \mathrm{~mL}$ distilled water per pot. This experiment consisted of 48 pots in total.

We measured the heights of 48 A. ordosica seedlings on December 20, 2010, and then marked each seedling with red paint at the base of the stem so that plant height could be measured accurately after the experiment. On the same day, the 50 remaining seedlings were dug up and cleaned, and their aboveground and root biomasses, plant height, and root length were measured. The plants in the pot experiment were watered with distilled water once a week. The water was applied via a metal needle to $2-\mathrm{cm}$ below the soil surface to prevent evaporation. During the experiment, the temperature in the greenhouse was kept at approximately $25^{\circ} \mathrm{C}$ during the day and $18^{\circ} \mathrm{C}$ at night.

The pot experiment ended on January 30, 2011, after the A. ordosica seedlings had grown for $40 \mathrm{~d}$. The 48 seedlings were dug up and cleaned, and then aboveground and root biomasses, plant height, and root lengths were determined.

\subsection{Soil sample analyses}

In the laboratory, the soil samples were air-dried, ground, and then sieved through an 80-mesh sieve. We used the aerometric method [18] to determine $\mathrm{CaCO}_{3}$ content, and AP was determined with $0.5 \mathrm{~mol} \mathrm{~L}^{-1} \mathrm{NaHCO}_{3}$ extraction and the molybdenum stibium anti-color method.

\subsection{Data analyses}

(i) Calculation of growth rate. Using plant height as the independent variable and plant root length, aboveground biomass, and root weight as dependent variables, we constructed a fitting curve using SPSS 13.0 software and chose the optimal regression equation that showed the best fit to the 50 seedlings measured at the start of the experiment. Then, using the initial plant heights of 48 A. ordosica seedlings measured previously as independent variables, we used the optimal regression equation above to estimate the initial growth status of root length, aboveground biomass, and root weight of these 48 seedlings at the start of the experiment. Thus, the initial plant heights measured previously, the estimated aboveground biomass, root length and root weight served as baseline data for the start of the experiment. Lastly, we calculated the amount of growth using the initial baseline data and the measured data at the end of the experiment, and growth rates were calculated by dividing the amount of growth by the experimental growth period (40 d).

(ii) Data analysis. Using soil nutrient as the horizontal ordinate and plant density as the vertical ordinate, we carried out regression analyses for all of the variables using Excel 2003 software. The variable distribution diagrams were constructed with Surfer 6.0 software and the descriptive statistics and the significance tests were performed using SPSS 13.0 software.

\section{Results and analysis}

\subsection{Variations in soil stoichiometry of the $\mathrm{CaCO}_{3} / \mathrm{AP}$ ratio in four sample plots of $A$. ordosica communities}

Before analyzing the effects of soil stoichiometry of the $\mathrm{CaCO}_{3} / \mathrm{AP}$ ratio on plant density, we characterized the soil $\mathrm{CaCO}_{3} / \mathrm{AP}$ ratios (magnitudes and variations) in the study areas.

In the two-dimensional sample plots in Yulin, soil Ca$\mathrm{CO}_{3} / \mathrm{AP}$ ratios varied with the terrain of the fixed sand dune. This was because the sand dunes were fixed only for a short time and because the distribution of A. ordosica plants was affected by the terrain of the dune. The soil $\mathrm{CaCO}_{3} / \mathrm{AP}$ ratios were relatively higher in the west of the sample plot, and relatively lower in the center and east of the plot (Figure 1(a)). However, apart from a small area in the southwest of the plot, the $\mathrm{CaCO}_{3} / \mathrm{AP}$ ratios were reasonably consistent within the plot in the overgrown sand dune of A. ordosica+ A. frigida community in Alxa (Figure 1(b)). This was because the plant community in this area was undergoing succession. In this plot, the spatial distribution characteristics of soil $\mathrm{CaCO}_{3} / \mathrm{AP}$ ratios would affect the distribution of the various plant species.

Theoretically, there are 3 ways in which the soil stoichiometry of the $\mathrm{CaCO}_{3} / \mathrm{AP}$ ratio can increase. First, the $\mathrm{CaCO}_{3} / \mathrm{AP}$ ratio can increase because of increased $\mathrm{CaCO}_{3}$ and decreased available phosphorus; second, it can result from the amplitude of the increase in $\mathrm{CaCO}_{3}$ being greater than that of the available phosphorus; third, it can result when the decrease in soil $\mathrm{CaCO}_{3}$ is less than the decrease in soil available phosphorus.

Descriptive statistics for one-dimensional sample plots indicated that the $\mathrm{CaCO}_{3} / \mathrm{AP}$ ratio in the semi-fixed sand dune A. ordosica community in Yulin (0.43) was less than that in Shapotou (1.08) (Table 1). According to the mean and coefficients of variation of these two plots, the higher 
soil $\mathrm{CaCO}_{3} / \mathrm{AP}$ ratio in the fixed sand dune in Shapotou was because the soil $\mathrm{CaCO}_{3}$ increased while AP decreased.

Descriptive statistics for two-dimensional sample plots (Table 2) indicated that the soil $\mathrm{CaCO}_{3} / \mathrm{AP}$ ratio in the fixed sand dune A. ordosica community in Yulin (0.66) was markedly less than that in the overgrown sand dune $A$. ordosica $+A$. frigida community in Alxa (10.61). This very high ratio was because the soil $\mathrm{CaCO}_{3}$ increased significantly while AP decreased significantly. Tables 1 and 2 showed that, among the 4 sample plots, soil $\mathrm{CaCO}_{3} / \mathrm{AP}$ ratios in the fixed sand dune in Yulin were lower but the coefficients were greater, which resulted from the greater variation of soil $\mathrm{CaCO}_{3}$ content in this community.

Further analysis indicated that, compared with the semifixed sand dune A. ordosica community in Yulin, the higher soil $\mathrm{CaCO}_{3} / \mathrm{AP}$ ratio in the fixed sand dune $A$. ordosica community in Yulin was because the increase in $\mathrm{CaCO}_{3}$ was greater than the increase in available phosphorus.
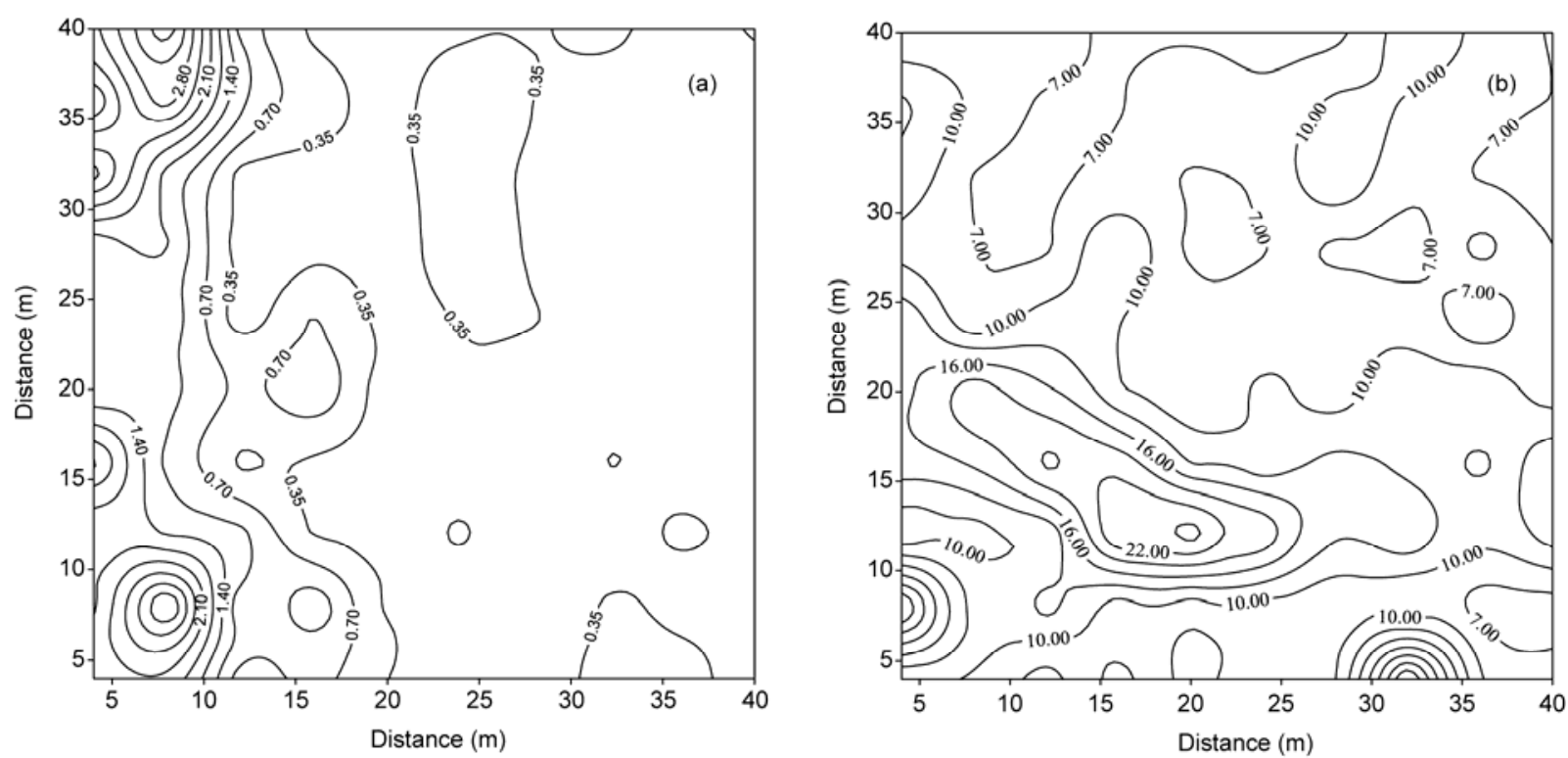

Figure 1 Spatial distribution of soil $\mathrm{CaCO}_{3} / \mathrm{AP}$ ratios in fixed dune of $A$. ordosica community (Yulin) and in overgrown sand dune of $A$. ordosica $+A$. frigida community (Alxa). (a) Sample plot of A. ordosica community in Yulin; (b) sample plot of A. ordosica $+A$. frigida community in Alxa.

Table 1 Statistics of soil $\mathrm{CaCO}_{3} / \mathrm{AP}$ ratios in fixed sand dune sample plot of $A$. ordosica community in Shapotou and semi-fixed sand dune sample plot of A. ordosica community in Yulin

\begin{tabular}{|c|c|c|c|c|c|c|c|c|c|c|}
\hline Index & Site & Num & Mean & Min & Max & SE & $\mathrm{SD}$ & Kurt & Skew & $\mathrm{CV}(\%)$ \\
\hline \multirow{2}{*}{$\begin{array}{l}\mathrm{CaCO}_{3} \text { content } \\
\quad\left(\mathrm{g} \mathrm{kg}^{-1}\right)\end{array}$} & Shapotou & 50 & 4.91 & 1.36 & 10.01 & 0.30 & 2.10 & 0.27 & 0.69 & 42.77 \\
\hline & Yulin & 50 & 2.16 & 0.64 & 9.02 & 0.18 & 1.26 & 17.41 & 3.42 & 58.33 \\
\hline \multirow{2}{*}{$\begin{array}{l}\text { AP content } \\
\left(\mathrm{mg} \mathrm{kg}^{-1}\right)\end{array}$} & Shapotou & 50 & 4.78 & 2.78 & 7.03 & 0.14 & 0.97 & -0.11 & 0.42 & 20.29 \\
\hline & Yulin & 50 & 5.01 & 3.74 & 6.86 & 0.11 & 0.78 & -0.61 & 0.43 & 15.57 \\
\hline $\mathrm{CaCO}_{3} / \mathrm{AP}$ ratios & Shapotou & 50 & 1.08 & 0.27 & 2.08 & 0.07 & 0.51 & -0.69 & 0.52 & 47.22 \\
\hline
\end{tabular}

Table 2 Statistics of soil $\mathrm{CaCO}_{3} / \mathrm{AP}$ ratios in fixed sand dune sample plot of A. ordosica community in Yulin and overgrown sand dune sample plot of $A$. ordosica + A. frigida community in Alxa

\begin{tabular}{|c|c|c|c|c|c|c|c|c|c|c|}
\hline Index & Site & Num & Mean & Min & Max & SE & SD & Kurt & Skew & $\mathrm{CV}(\%)$ \\
\hline \multirow{2}{*}{$\begin{array}{l}\mathrm{CaCO}_{3} \text { content } \\
\left(\mathrm{g} \mathrm{kg}^{-1}\right)\end{array}$} & Alxa & 100 & 18.89 & 9.10 & 54.81 & 0.66 & 6.61 & 9.38 & 2.43 & 34.99 \\
\hline & Yulin & 100 & 3.55 & 0.21 & 19.13 & 0.39 & 3.86 & 3.66 & 2.01 & 108.73 \\
\hline $\begin{array}{l}\text { AP content } \\
\left(\mathrm{mg} \mathrm{kg}^{-1}\right)\end{array}$ & Yulin & 100 & 6.22 & 1.45 & 12.56 & 0.23 & 2.26 & -0.19 & 0.21 & 36.33 \\
\hline \multirow{2}{*}{$\mathrm{CaCO}_{3} / \mathrm{AP}$ ratios } & Alxa & 100 & 10.61 & 3.84 & 32.16 & 0.53 & 5.27 & 4.24 & 1.93 & 49.67 \\
\hline & Yulin & 100 & 0.66 & 0.03 & 3.77 & 0.08 & 0.76 & 5.61 & 2.31 & 115.15 \\
\hline
\end{tabular}


Meanwhile, compared with the fixed sand dune A. ordosica community in Shapotou, the higher soil $\mathrm{CaCO}_{3} / \mathrm{AP}$ ratio in the overgrown sand dune in Alxa was because the $\mathrm{CaCO}_{3}$ content increased while the AP decreased.

Because there were different reasons for the higher $\mathrm{CaCO}_{3} / \mathrm{AP}$ ratios, the effect of the soil $\mathrm{CaCO}_{3} / \mathrm{AP}$ ratio on plant density in each plant community might be different. This is discussed in detail below.

\subsection{Effect of soil stoichiometry of $\mathrm{CaCO}_{3} / \mathrm{AP}$ ratio on plant density in $4 \mathrm{~A}$. ordosica community sample plots}

Regression analysis indicated that, with the increase in soil $\mathrm{CaCO}_{3} / \mathrm{AP}$ ratios, the density of $A$. ordosica in the community in the semi-fixed sand dune in Yulin increased logarithmically and significantly $(P=0.016$; Figure 2(a)). However, the density of $A$. ordosica density decreased linearly and significantly in the community in the fixed sand dune in Shapotou with increasing $\mathrm{CaCO}_{3} / \mathrm{AP}$ ratios $(P=0.025$; Figure 2(b)). As shown in Figure 2, the soil $\mathrm{CaCO}_{3} / \mathrm{AP}$ ratios in both sample plots were less than 2.5 , ranging from 0.3 to 0.6 in the semi-fixed sand dune in Yulin and from 0.3 to 1.8 in the fixed sand dune in Shapotou. This indicated that the effects of the soil $\mathrm{CaCO}_{3} / \mathrm{AP}$ ratio on A. ordosica density differed among different habitats, even though the amplitudes of the $\mathrm{CaCO}_{3} / \mathrm{AP}$ ratios were similar.
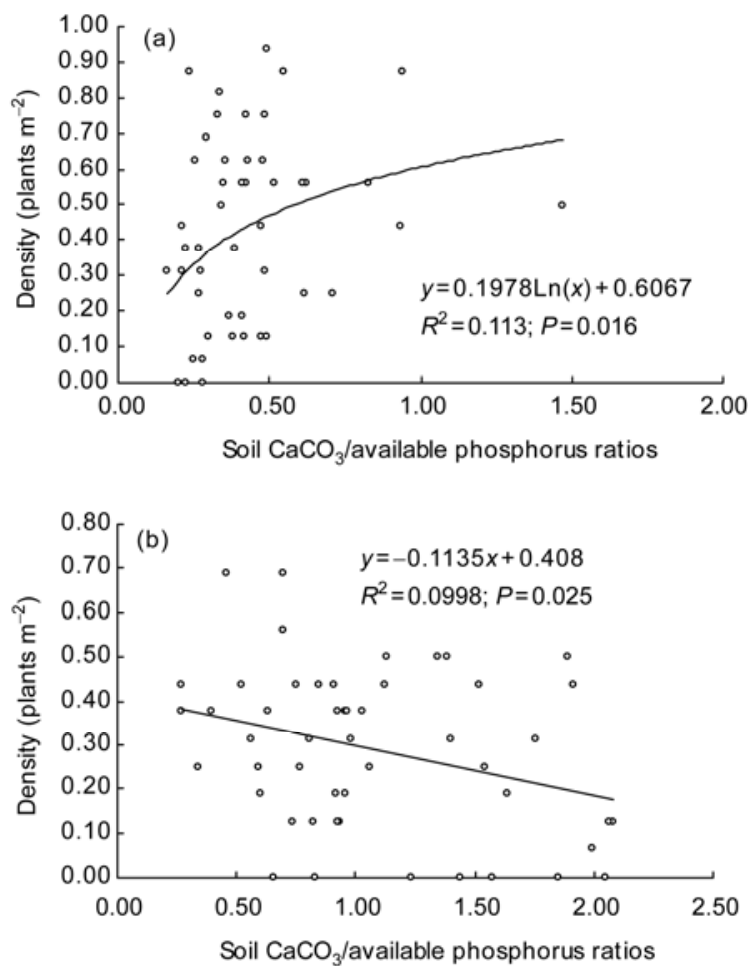

Figure 2 Relationship between $A$. ordosica density and soil $\mathrm{CaCO}_{3} / \mathrm{AP}$ ratio in one-dimensional sample plots of $A$. ordosica communities in Yulin and Shapotou. (a) One-dimensional sample plot of A. ordosica community in Yulin; (b) one-dimensional sample plot of A. ordosica community in Shapotou.
Regression analysis indicated that as the soil $\mathrm{CaCO}_{3} / \mathrm{AP}$ ratio increased, the density of $A$. ordosica in the fixed sand dune community of $A$. ordosica in Yulin increased significantly and logarithmically $(P=0.000$, Figure 3$)$. In the overgrown sand dune community of $A$. ordosica $+A$. frigida in Alxa, the density of $A$. ordosica also increased significantly and logarithmically $(P=0.002$; Figure $4(b))$ while the density of $A$. frigida decreased significantly and logarithmically $(P=0.002$; Figure 4(b)). In the fixed sand dune in Yulin, the soil $\mathrm{CaCO}_{3} / \mathrm{AP}$ ratios ranged from 0.1 to 1.5 ; but in the overgrown sand dune in Alxa, the soil $\mathrm{CaCO}_{3} / \mathrm{AP}$ ratios ranged from 5 to 15 . This indicated that in different habitats, though the amplitude of soil $\mathrm{CaCO}_{3} / \mathrm{AP}$ ratios was different, the effect of $\mathrm{CaCO}_{3} / \mathrm{AP}$ ratio on $A$. ordosica density may be

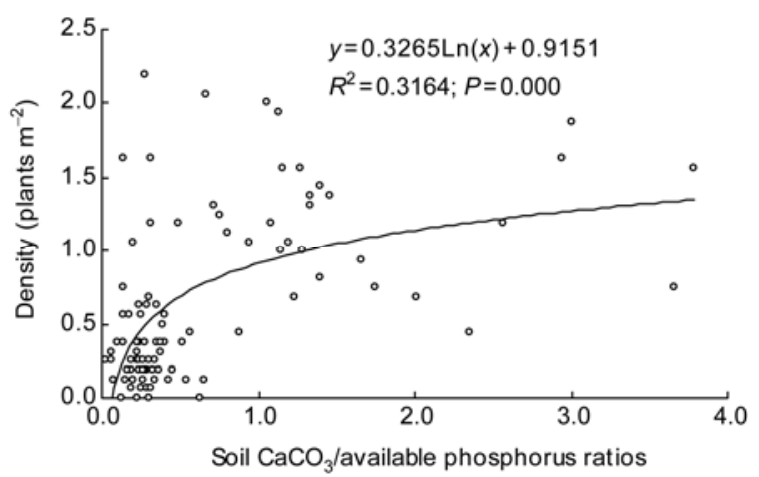

Figure 3 Relationship between A. ordosica density and soil $\mathrm{CaCO}_{3} / \mathrm{AP}$ ratios in two-dimensional sample plot of A. ordosica community in Yulin.
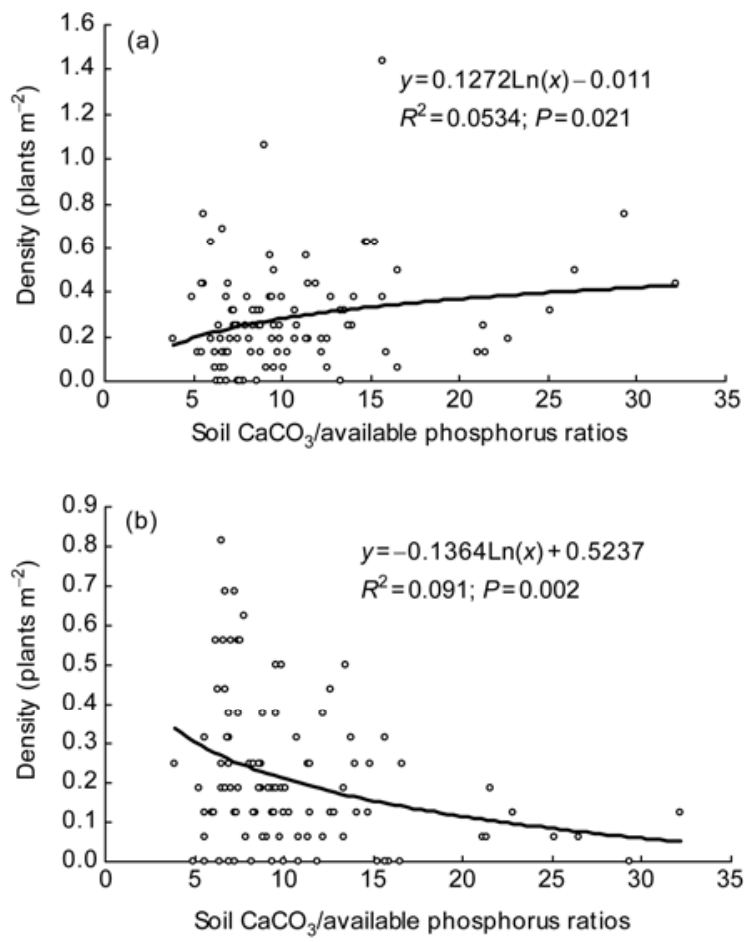

Figure 4 Relationships between the densities of A. ordosica and A. frigida and soil $\mathrm{CaCO}_{3} / \mathrm{AP}$ ratios in two-dimensional sample plot of $A$. ordosica + A. frigida community in Alxa. (a) A. ordosica; (b) A. frigida. 
the same; however, in the same habitat, similar $\mathrm{CaCO}_{3} / \mathrm{AP}$ ratios might have different effects on the density of different species.

\subsection{Orthogonal test on pot-grown $A$. ordosica seedlings}

We conducted a pot experiment with an orthogonal design using A. ordosica seedlings and different ratios of $\mathrm{CaCO}_{3}$ and available phosphorus. As shown in Figure 5, soil AP had the greatest impact on the aboveground biomass of $A$. ordosica, while the interaction of soil $\mathrm{CaCO}_{3}$ and $\mathrm{AP}(\mathrm{Ca}-$ $\mathrm{CO}_{3} \times \mathrm{AP}$ in Figure 5, i.e., soil $\mathrm{CaCO}_{3} / \mathrm{AP}$ ratio) also had greater impact. However, the soil stoichiometry of the $\mathrm{Ca}$ $\mathrm{CO}_{3}$ /AP ratio had the greatest impact on root weight of $A$. ordosica seedlings, while soil $\mathrm{CaCO}_{3}$ and $\mathrm{AP}$ did not have significant effects as single factors.

\section{Discussion}

The soil stoichiometry of the $\mathrm{CaCO}_{3} / \mathrm{AP}$ ratio can affect plant density. This may be an effect of variations in biological stoichiometry that result from changes in soil stoichiometry. The types and amplitudes of increases in soil stoichiometry are also important.

Our investigations in 2004 indicated that increasing soil $\mathrm{CaCO}_{3} / \mathrm{AP}$ ratios resulted in increased $A$. ordosica density in the semi-fixed sand dune A. ordosica community in $\mathrm{Yu}-$ lin, but decreased density in the fixed sand dune A. ordosica community in Shapotou. This observation indicated that the soil stoichiometry of the $\mathrm{CaCO}_{3} / \mathrm{AP}$ ratio was a significant factor influencing changes in plant density. The change in $A$. ordosica density in the fixed sand dune population in Shapotou was consistent with previous research, while the increase in density in the semi-fixed sand dune population in Yulin was somewhat confusing. The sample plot in Shapotou is located in the Tengger Desert, an arid area. With fixation of the dune, active microorganisms in the soil promoted decomposition of litter of $A$. ordosica, accelerating

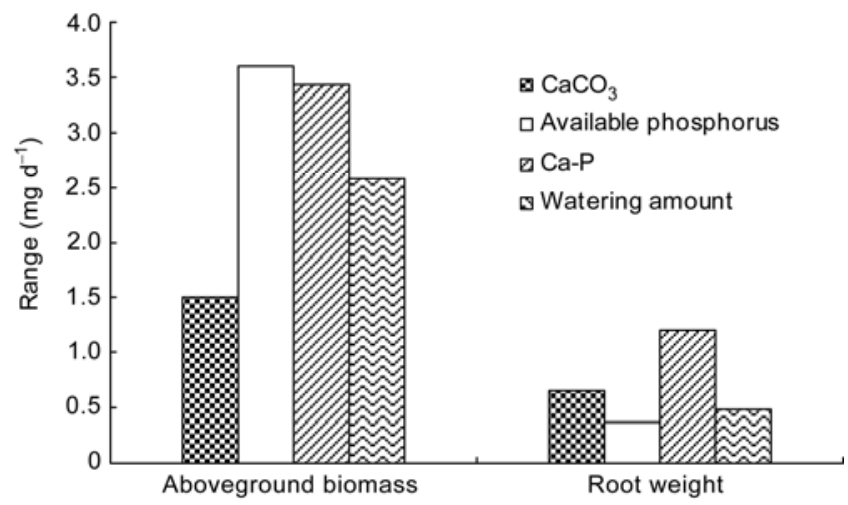

Figure 5 Results of three-factor orthogonal design pot experiment using A. ordosica seedlings. the release of $\mathrm{Ca}^{2+}$ ions [19]. Therefore, in the Shapotou area, the total $\mathrm{Ca}^{2+}$ content in the soil was relatively high, resulting in a large reservoir of exchangeable calcium [13] that directly leads to the formation of the insoluble Ca-P phase [10,20], e.g., dicalcium phosphate and octacalcium phosphate [11,21]. On the other hand, with fixation of the dune, the soil $\mathrm{CaCO}_{3}$ content in Shapotou increased significantly [17], which increased soil $\mathrm{pH}$ and precipitated $\mathrm{Ca}^{2+}$ and phosphorus [10,22], decreasing availability of soil phosphorus [23]. Thus, the soil stoichiometry of the Ca$\mathrm{CO}_{3}$ /AP ratio was negatively correlated with $A$. ordosica density in Shapotou. However, in the semi-fixed sand dune of Yulin, the soil $\mathrm{CaCO}_{3} / \mathrm{AP}$ ratio was positively correlated with A. ordosica density; that is, the increase in the soil $\mathrm{CaCO}_{3} / \mathrm{AP}$ ratio and the increase in soil $\mathrm{CaCO}_{3}$ content meant that the limitation of soil $\mathrm{CaCO}_{3}$ on phosphorus was not so severe. As noted above, the semi-fixed sand dune of A. ordosica in Yulin is located in Mu Us Sand Land, a semi-arid area. The average annual precipitation in the $\mathrm{Yu}-$ lin sample plot $(414 \mathrm{~mm})$ was greater than that in the Shapotou sample plot $(186.6 \mathrm{~mm})$, the average soil $\mathrm{CaCO}_{3}$ content in the Yulin sample plot $\left(2.16 \mathrm{~g} \mathrm{~kg}^{-1}\right)$ was lower than that in the Shapotou sample plot $\left(4.91 \mathrm{~g} \mathrm{~kg}^{-1}\right)$, while the average AP content in Yulin $\left(5.01 \mathrm{mg} \mathrm{kg}^{-1}\right)$ was greater than that in the Shapotou sample plot $\left(4.78 \mathrm{mg} \mathrm{kg}^{-1}\right)$. Therefore, the soil $\mathrm{CaCO}_{3}$ only slightly limited the available phosphorus. Meanwhile, the relatively lower level of soil $\mathrm{CaCO}_{3}$ meant that $A$. ordosica was subjected to calciumlimited conditions. Because of the importance of $\mathrm{Ca}^{2+}$ ions for drought-tolerance of plants [24-26], under calcium-limited conditions, an increase in $\mathrm{Ca}^{2+}$ ions can favor plant growth. Under calcium-deficient conditions, various processes in the cell compete for calcium [27]. In the semi-fixed sand dune sample plot in Yulin, $\mathrm{Ca}^{2+}$ ions dissolved out from soil $\mathrm{CaCO}_{3}$ and there was relatively high phosphorus availability, both of which were advantageous for plant growth. Thus, the soil stoichiometry of $\mathrm{CaCO}_{3} / \mathrm{AP}$ ratios was positively correlated with $A$. ordosica density in the semi-fixed sand dune in Yulin.

Next, we examined whether the relationship between the soil $\mathrm{CaCO}_{3} / \mathrm{AP}$ ratio and $A$. ordosica density was the same for the fixed sand dune A. ordosica community in Yulin. In 2009, we also investigated the $A$. ordosica community in the fixed sand dune system in Yulin. Our results indicated that the density of $A$. ordosica increased significantly with increasing soil $\mathrm{CaCO}_{3} / \mathrm{AP}$ ratios. Therefore, the relationship between the soil $\mathrm{CaCO}_{3} / \mathrm{AP}$ ratio and the density of $A$. ordosica was the same in A. ordosica communities in both the fixed and semi-fixed sand dune systems in Yulin. As discussed in the results section, the fixed dune of A. ordosica community in Yulin showed slightly higher soil $\mathrm{CaCO}_{3}$, available phosphorus, and soil $\mathrm{CaCO}_{3} / \mathrm{AP}$ ratios compared with the semi-fixed sand dune community, but the amplitudes were similar. Thus, A. ordosica plants were growing in calcium-limited conditions in the fixed dune plot in Yulin, 
and hence, the soil $\mathrm{CaCO}_{3} / \mathrm{AP}$ ratio was still positively correlated with $A$. ordosica density.

However, in 2009, we investigated the overgrown dune plot of the A. ordosica + A. frigida community in the Tengger Desert, Alxa, and obtained completely different results. In the present study, the density of $A$. ordosica increased with increasing soil $\mathrm{CaCO}_{3} / \mathrm{AP}$ ratios in the overgrown sand dune sample plot of the $A$. ordosica $+A$. frigida community in Alxa. The results of statistical analyses showed that the average soil $\mathrm{CaCO}_{3}$ content in the sample plot in Alxa (18.89 $\mathrm{g} \mathrm{kg}^{-1}$ ) was far greater than that in the sample plot in Shapotou, while the average soil AP content $\left(1.96 \mathrm{~g} \mathrm{~kg}^{-1}\right)$ was far less than that in the sample plot of Shapotou. This resulted in a far greater average soil $\mathrm{CaCO}_{3} / \mathrm{AP}$ ratio in Alxa (10.61) than in Shapotou (1.08). Therefore, there were marked differences in the amplitudes of soil $\mathrm{CaCO}_{3}$ content, AP content, and soil $\mathrm{CaCO}_{3} / \mathrm{AP}$ ratios between the plots in Alxa and Shapotou. Thus, we inferred that the increased restriction of soil $\mathrm{CaCO}_{3}$ on phosphorus availability created severely limited phosphorus conditions for growth of plants in the overgrown dune plot of the A. ordosica $+A$. frigida community in Alxa. This resulted from the significant increase in soil $\mathrm{CaCO}_{3}$ and the significant decrease of available phosphorus. As discussed above for the sample plot in Shapotou, the increase of soil $\mathrm{CaCO}_{3}$ content in an arid area would restrict phosphorus availability, resulting in the decrease in $A$. ordosica density with increasing soil $\mathrm{CaCO}_{3} /$ AP ratios in Shapotou. However, in the Alxa sample plot, $A$. ordosica density increased with increasing soil $\mathrm{CaCO}_{3} / \mathrm{AP}$ ratios. What is the reason for this discrepancy? We speculate that the difference was because of the significant increase in soil $\mathrm{CaCO}_{3}$ content and the significant decrease in AP content. In the sample plot in Alxa, the total biomass of the plant community remained constant over a long period because of the long-term fixation of the due (almost 60 years). Therefore, most of the phosphorus released by organic matter/leaf litter was taken up by plants, leading to a significant decrease of available phosphorus in the soil. However, the soil $\mathrm{CaCO}_{3}$ content increased with increasing organic matter [28] because little soil $\mathrm{CaCO}_{3}$ was used by plants. In this case, therefore, the effects of the high soil $\mathrm{CaCO}_{3} / \mathrm{AP}$ ratios, which reflected high soil $\mathrm{CaCO}_{3}$ content but low AP content, on the density of A. ordosica actually reflected phosphorus limitation. That is to say, the soil $\mathrm{CaCO}_{3}$ more strongly restricted phosphorus availability, and an increase in the soil $\mathrm{CaCO}_{3} / \mathrm{AP}$ ratio resulted in a decrease in available phosphorus. In the present study, in the sample plot in Alxa, the increase in the density of A. ordosica with increasing soil $\mathrm{CaCO}_{3} / \mathrm{AP}$ ratio was related to the decrease in soil available phosphorus. In other words, the density of A. ordosica decreased with increasing soil AP in the plot in Alxa. In fact, regression analysis indicated that the density of A. ordosica decreased with increasing soil available phosphorus in the overgrown sand dune of Alxa (regression equation: $\left.y=0.1375 \operatorname{Ln}(x)+0.3607, R^{2}=0.0552, P=0.019\right)$.
Therefore, in the sample plot in Alxa, when soil $\mathrm{CaCO}_{3}$ content increased alongside a decrease in soil, the density of A. ordosica increased with increasing soil $\mathrm{CaCO}_{3} / \mathrm{AP}$ ratios.

It is worth pointing out that in the overgrown sand dune A. ordosica $+A$. frigida community in Alxa, the plant community is in succession, i.e., A. frigida is replacing $A$. ordosica. In the present study, increasing soil $\mathrm{CaCO}_{3} / \mathrm{AP}$ ratios were associated with increased density of A. ordosica and decreased density of $A$. frigida, which indicated that changes in soil $\mathrm{CaCO}_{3} / \mathrm{AP}$ ratios can affect succession of plant communities. This is not only because differences in reproductive strategies between different species in the $\mathrm{Ar}$ temisia genus [29], or the influence of water on plant growth in arid regions [30,31], but also because of the impact of the soil $\mathrm{CaCO}_{3} / \mathrm{AP}$ ratio, and especially soil available phosphorus. As mentioned above, A. ordosica density decreased with the increase of soil AP in the overgrown sand dune in Alxa. On the other hand, in this plant community, A. frigida density increased with increasing soil AP (regression equation: $y=-0.1985 \operatorname{Ln}(x)+0.0943, R^{2}=0.1703$, $P=0.000$ ). There is a strong relationship between phosphorus use efficiency and plant drought resistance [32]; therefore, A. frigida has greater phosphorus-use efficiency than $A$. ordosica. Moreover, there are differences in root mortality and root exudation between A. ordosica and A. frigida [21]. All of these differences resulted in the increase in the density of $A$. ordosica and the decrease in the density of $A$. frigida with increasing soil $\mathrm{CaCO}_{3} / \mathrm{AP}$ ratios. On the other hand, the average soil $\mathrm{CaCO}_{3} / \mathrm{AP}$ ratio in the sample plot in Alxa was 10.61. Thus, we could infer that in the desert-steppe of this arid region [33], when the soil stoichiometry of the $\mathrm{CaCO}_{3} / \mathrm{AP}$ ratio exceeds 10 , plant succession within the community may occur as the soil $\mathrm{CaCO}_{3} / \mathrm{AP}$ ratio increases.

From previous research, it is clear that both soil $\mathrm{CaCO}_{3}$ $[34,35]$ and AP [23,36] are important for plant growth. In this study, we have shown that the soil $\mathrm{CaCO}_{3} / \mathrm{AP}$ ratio also influences the density of $A$. ordosica. Which factor among $\mathrm{CaCO}_{3}$, available phosphorus, and the $\mathrm{CaCO}_{3} / \mathrm{AP}$ ratio in soil has the greatest impact on plant growth? To address this question, in 2010 we performed a pot experiment with a three-factor orthogonal design using A. ordosica seedlings. The experimental conditions were based on the local status of soil $\mathrm{CaCO}_{3}$ and $\mathrm{AP}$ as well as precipitation in the natural distribution area of $A$. ordosica. The results indicated that the soil $\mathrm{CaCO}_{3} / \mathrm{AP}$ ratio had the greatest influence on aboveground biomass and root weight of $A$. ordosica seedlings. This indicated that soil $\mathrm{CaCO}_{3} / \mathrm{AP}$ ratio had an important impact on the A. ordosica biomass. The influence of soil $\mathrm{CaCO}_{3} / \mathrm{AP}$ ratio on plant biomass would ultimately lead to a change in plant density, which is consistent with our results above.

However, as discussed above, the influence of soil stoichiometry of the $\mathrm{CaCO}_{3} / \mathrm{AP}$ ratio on A. ordosica density was related to the climatic zone and the types of increases in the $\mathrm{CaCO}_{3} / \mathrm{AP}$ ratio. In the arid region, when the soil 
$\mathrm{CaCO}_{3} / \mathrm{AP}$ ratio was less than 2.5 , the density of $A$. ordosi$c a$ increased as the soil $\mathrm{CaCO}_{3} / \mathrm{AP}$ ratio increased. When the soil $\mathrm{CaCO}_{3} / \mathrm{AP}$ ratio was within the same amplitude, i.e., below 5, even though the increase in the $\mathrm{CaCO}_{3}$ content was greater than that of soil available phosphorus, the $A$. ordosica density increased with increasing soil $\mathrm{CaCO}_{3} / \mathrm{AP}$ ratios. This result indicated that the relationship between the soil $\mathrm{CaCO}_{3} / \mathrm{AP}$ ratio and the A. ordosica density remained the same. However, in the arid region, although the soil $\mathrm{CaCO}_{3} / \mathrm{AP}$ ratio was within the same amplitude, i.e., less than 2.5, the density of A. ordosica decreased with increasing soil $\mathrm{CaCO}_{3} / \mathrm{AP}$ ratios, which was very different from the case in the semi-arid region. When the amplitude of soil $\mathrm{CaCO}_{3} / \mathrm{AP}$ ratio was greater, that is, ranging from 5 to 15 (average, 10.61), the soil $\mathrm{CaCO}_{3}$ content increased significantly while the soil AP decreased significantly. In this case, the density of A. ordosica increased with increasing soil $\mathrm{CaCO}_{3} / \mathrm{AP}$ ratios, which meant that the relationship between the soil $\mathrm{CaCO}_{3} / \mathrm{AP}$ ratio and the density of $A$. ordosica changed. Thus, if the reasons for the increase in the $\mathrm{CaCO}_{3} / \mathrm{AP}$ ratio differ, the effect of soil stoichiometry of the $\mathrm{CaCO}_{3} / \mathrm{AP}$ ratio on plant density will change.

1 Elser J J, Fagan W F, Denno R F, et al. Nutritional constraints in terrestrial and fresh water food webs. Nature, 2000, 408: 578-580

2 Wang S Q, Yu G R. Ecological stoichiometry characteristics of ecosystem carbon, nitrogen and phosphorus elements (in Chinese). Acta Ecol Sin, 2008, 28: 3937-394

3 Wu W, He X D, Zhou Q X. Review on N:P stoichiometry in ecosystem (in Chinese). J Desert Res, 2010, 30: 296-302

4 Elser J J, Sterner R W, Gorokhova E, et al. Biological stoichiometry from genes to ecosystems. Ecol Lett, 2000, 3: 540-550

5 Koerselman W, Meuleman A F M. The vegetation N:P ratio: A new tool to detect the nature of nutrient limitation. J Appl Ecol, 1996, 33: 1441-1450

6 Venterink H O, Wassen M J, Verkroost A W M, et al. Species richness-production patterns differ between $\mathrm{N}$-, P-, and K-limited wetlands. Ecology, 2003, 84: 2191-2199

7 Silberbush M, Waisel Y, Kafkafi U. The role of soil phosphorus in differentiation of edaphic ecotypes in aegilops peregrine. Oecologia, 1981, 49: 419-424

8 Hinsinger P. Bioavailability of soil inorganic $\mathrm{P}$ in the rhizosphere as affected by root-induced chemical changes: A review. Plant Soil, 2001, 237: 173-195

9 Duniway M C, Herrick J E, Monger H C. Spatial and temporal variability of plant-available water in calcium carbonate-cemented soils and consequences for arid ecosystem resilience. Oecologia, 2010, 163: 215-226

10 Tunesi S, Poggi V, Gessa C. Phosphate adsorption and precipitation in calcareous soils: The role of calcium ions in solution and carbonate minerals. Nutr Cycl Agroecosyst, 1999, 53: 219-227

11 Von Wandruszka R. Phosphorus retention in calcareous soils and the effect of organic matter on its mobility. Geochem Trans, 2006, 7: 6

12 Cross A F, Schlesinger W H. Biological and geochemical controls on phosphorus fractions in semiarid soils. Biogeochem, 2001, 52: 155-172

13 Braschi I, Ciavatta C, Giovannini C, et al. Combined effects of water and organic matter on phosphorus availability in calcareous soils. Nutr Cycl Agroecosyst, 2003, 67: 67-74

14 Tilman D. The resource-ratio hypothesis of plant succession. Am Nat, 1985, 125: 827-852
15 Zhu Z D. Desert in China (Recension) (in Chinese). Beijing: Science Press, 1980

16 Zhao X L. Discussion on sand-fixing plants in Shapotou area. In: Institute of Desert Research, Chinese Academy of Sciences, Lanzhou. Study on Controlling Shifting Sand in Tengri Desert (2nd) (in Chinese). Yinchuan: Ningxia People Press, 1991. 27-57

17 Wang H T, Xue P P, He X D, et al. Changes of soil substrates in Artemisia Ordosica succession series (in Chinese). Acta Sci Naturalium Univ Nankaiensis, 2007, 40: 87-91

18 Bao S D. Analytical Methods of Soil and Agro-chemistry (in Chinese). Beijing: Chinese Agriculture Press, 2000

19 Wang H T, Zhang Y T, He X D, et al. Litterfall and decomposition of biomass and soil respiration of Artemisia Ordosica communities in arid region (in Chinese). J Desert Res, 2007, 27: 455-459

20 Carreira J A, Vinegla B, Laytha K. Secondary $\mathrm{CaCO}_{3}$ and precipitation of P-Ca compounds control the retention of soil $\mathrm{P}$ in arid ecosystems. J Arid Environ, 2006, 64: 460-473

21 Ma B, Zhou Z Y, Zhang C P, et al. Inorganic phosphorus fractions in the rhizosphere of xerophytic shrubs in the Alxa Desert. J Arid Environ, 2009, 73: 55-61

22 Zhao Q, Zeng D H, Lee D K, et al. Effects of Pinus sylvestris var. mongolica afforestation on soil phosphorus status of Keerqin Sandy Lands in China. J Arid Environ, 2007, 69: 569-582

23 Arnesen G, Beck P S A, Engelskjon T. Soil acidity, content of carbonates and available phosphorus are the soil factors best correlated with alpine vegetation: Evidence from Trom, North Norway. Arc Antarc Alpine Res, 2007, 39: 189-199

24 Larkindale J, Knight M R. Prodection against heat stress-induced oxidative damage in Arabidopsis involves calcium, abscisic acid, ethylene, and salicylic acid. Plant Physiol, 2002, 128: 682-695

25 Kawano T, Sahashi N, Takahashi K, et al. Salicylic acid induces extracellular superoxide generation followed by an increase in cytosolic calcium ion in tobacco suspension culture: The earliest events in salicylic acid signal transduction. Plant Cell Physiol, 1998, 39: 721-730

26 Peng H X, Sivasithamparam K, Turner D W. Chlamydospore germination and fusarium wilt of banana plantlets in suppressive and conductive soils are affected by physical and chemical factors. Soil Biol Biochem, 1999, 31: 1363-1374

27 Simon E W. The symtoms of calcium deficiency in plants. New Phytol, 1978, 80: 1-15

28 Zhang N, He X D, Gao Y B, et al. Pedogenic carbonate and soil dehydrogenase activity in response to soil organic matter in Artemisia ordosica community. Pedosph, 2010, 20: 229-235

29 Liu Z M. Plant Reproductive Strategy in Horqin Sandy Land (in Chinese). Beijing: Meteorological Press, 2010

30 Zhao W Z, Cheng G D. Comments on several questions of ecological hydrological process in arid region (in Chinese). Chin Sci Bull, 2001, 46: $1851-1857$

31 Yan J F, Chen X, Luo G P, et al. Response of spatial variability of underground water level on land-use and land-cover change in oasis in arid regions (in Chinese). Chin Sci Bull, 2006 (Chin Ver), 51(Suppl I): $42-48$

32 Gnanasire S. Cell membrane stability and leaf water relation as affected by phosphorus nutrition under stress in Maize. Soil Sci Plant Nutr, 1990, 36: 661-666

33 Liu Y X. Phyto-reclamation of sand dunes in northwest, north and northeast of China (in Chinese). J Desert Res, 1988, 8: 11-17

34 Zuo Y, Ren L, Zhang F, et al. Bicarbonate concentration as affected by soil water content controls iron nutrition of peanut plant in a calcareous soils. Plant Physiol Biochem, 2007, 45: 357-364

35 Pedersen J, Fransson A M, Olsson P A. Performance of Anisantha (Bromus) tectorum and Rumex acetosella in sandy calcareous soil. Flora, 2011, 206: 276-281

36 Holford I C R. Soil phosphorus: Its measurement, and its uptake by plants. Aus J Soil Res, 1997, 35: 227-240

Open Access This article is distributed under the terms of the Creative Commons Attribution License which permits any use, distribution, and reproduction in any medium, provided the original author(s) and source are credited. 